\title{
Fantasmas, visões, estática: metáforas em sentido literal
}

\author{
Eduardo Pellejero \\ PRofessor do DEPARTAMENTo DE FILOSOFIA DA UFRN
}

Bem-vindos, sonhadores acordados! VARDA, Agnès. ${ }^{1}$

Sabemos que, assim como não existe uma teoria da imagem, também não existe um método para olhar. A proliferação incomparável do sensível encontra no caráter polimorfo da atenção um suplemento inesperado. E, contudo, conduzir uma experiência no sensível não é uma expressão vazia. Conhecemos práticas e procedimentos, casos que merecem a nossa atenção e aconselham o estudo digamos: modos de ver e dar a ver.

O deslocamento da atenção é seguramente o procedimento mais simples, o mais imediato, o mais comum de todos. Não o único passo em direção à experiência estética, mas sem lugar para dúvidas um passo seguro. Os gregos cunharam um conceito para ele, um conceito que perpassaria toda a história da arte ocidental: a metáfora. Colocar fora de lugar aquilo que de ordinário damos por assente ou instalar o extraordinário no âmbito do familiar são modos exemplares desse procedimento que por vezes parece confundir-se com a atividade

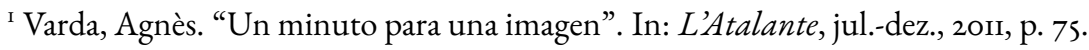


poética como um todo. A metáfora, nesse sentido, opera um espaçamento do olhar - abrindo "um parêntese para sonhar".

Tomemos o caso de uma espectadora comum. Estamos em 1954 e, em Paris, celebra-se um novo aniversário do fim da Segunda Guerra Mundial, que coincide, por acaso, com a tomada de Dien Bien Phu pelas tropas francesas. Os olhos de todo o mundo estão fixos nisso. As notícias se comprazem em façanhas militares e prestam homenagem aos caídos no Vietnã: imagens de atos patrióticos se sobrepõem ao inimaginável. Longe de Paris, perto de Calais, junto ao mar, Agnès Varda olha para outro lado. O faz através de uma câmara de placas, pelo que deixará um registo perene da sua visão. ${ }^{3}$ Acima, à direita, de costas para nós, dividido pela linha da costa, com os braços caídos aos lados, um homem contempla o mar. Está nu, como a criança que, a seus pés, sentada sobre a areia, olha na direção contrária, onde jaz uma cabra morta. Nós a vemos em primeiro plano, ocupando a esquina inferior direita: grávida de decomposição, os ossos desconjuntados numa postura impossível, a boca suspirando uma queixa surda, os olhos ainda abertos ("é curioso, quando você morre os seus olhos estão abertos"). ${ }^{4}$

Como, de resto, com qualquer imagem, não se trata de uma alegoria. ${ }^{5}$ Antes de qualquer leitura simbólica (e Varda é pródiga em sugestóes nesse sentido, ${ }^{6}$ a imagem revela um gesto elementar, porque desviando a nossa atenção das imagens

2 "Quando digo sonhar, refiro-me tanto às emoções como ao horror, a fascinação, a simpatia, a admiração, o prazer, a nostalgia, a cumplicidade no humor, em resumo, um sonhar ativo, o pequeno cinema dentro da cabeça de cada quem". (VARDA, Agnès. "Un minuto para una imagen”. In: L'Atalante, jul.-dez., 20II).

${ }^{3}$ A fotografia encontra-se disponível em numerosas versões na internet. Disponível em: www.a-n.co.uk/media/52525323. Acesso em: 19 nov. 2020.

${ }^{4}$ Tal é o comentário de uma das crianças que falam da foto no final do filme de Varda.

${ }^{5}$ Inclusive perante a fotografia de Fontcuberta, Varda (VARDA, Agnès. Une minute pour une image. França, 1982b) afirma não achar que se trate "de uma fábula, ou mesmo de uma alegoria”. O curta onde Varda fala da foto de Fontcuberta, assim como os outros curtas da série, encontra-se disponível na internet; por exemplo: https: //www.revistazum.com.br/ radar/agnes-varda-um-minuto-para-uma-imagem/.

6 "O outro dia vi nela os clichês da infância, desgarrada entre a imagem do pai direito e a imagem da mãe com seu enorme ventre, caída. Que pensa o menino? Vejo-o como um d' Os esquecidos, ou O pequeno principe, O pobre Blaise, Oliver Twist, ou qualquer outro menino, lendário e triste. Uma vez vi na imagem o enigma da esfinge, resolvido em três versóes, as três idades da vida. Mitologia, me fazes sonhar!” (VARDA, Agnès. Ulysse. França, 1982.) 
que ocupavam as primeiras páginas dos jornais e os horários de maior audiência da televisão naquele momento, póe em questão toda a ordem das imagens ao mesmo tempo que renova o nosso olhar.

Trata-se de uma operação poética. O deslocamento é uma metáfora. Não porque simbolicamente a imagem seja cifra visível de coisas invisíveis, mas porque, literalmente, coloca uma coisa no lugar de outra coisa, tornando visível o que de outra maneira permaneceria invisível. E isso, evidentemente, dá muito que pensar.

Com efeito, inclusive quando não suponha nenhum interesse particular para nós, e, nessa medida, não tenhamos a priori categorias para a enquadrar ou compreender (sempre que nos comportemos como espectadores comuns, e não, por exemplo, como intérpretes ou críticos), a foto de Varda suscita uma ingente atividade entre as nossas faculdades (sem propósito definido) - os nossos sentidos se aguçam, o sentido se prolifera.

É algo que podemos apreciar de forma clara quando, mais tarde, em I982, a própria Varda regressa sobre a imagem para lhe dedicar mais uma vez a sua atenção. ${ }^{7}$ Passaram 28 anos, ou 50.000 anos. Varda não lembra o que tinha em mente quando tomara a fotografia. ${ }^{8}$ As personagens da fotografia também não lembram bem ou simplesmente preferem não lembrar o que acontecia a elas. Porém, acolhendo a imagem, instalando-a no palco das suas histórias pessoais, uns e outros repetem mais uma vez a operação poética que lhe dera lugar: a imagem desloca-se, o nosso olhar desloca-se com ela.

Talvez esse seja o único mistério das imagens - que agitam fantasmas, agitando a nossa fantasia. E, no caso da foto em questão, não apenas o fantasma de uma cabra morta, mas todos os fantasmas que assombram a imagem: o espectro da juventude de Fouli, a assombração da doença de Ulysse, as recorrências do passado de Bienvenida. Esses fantasmas, é necessário insistir, não são invisíveis: nenhum fantasma é invisível. Está na essência dos fantasmas certa obstinação em não

7 O filme de Varda encontra-se disponível em vários lugares. Entre eles, disponível em: https://mubi.com/pt/films/ulysse. Acesso em I8 dez. 2020.

8 “(...) uma das minhas fotografias levava vinte anos no atelier, sobre a porta de um armário. Estava claro que era muito importante mas me perguntava porquê. E essa pergunta converte-se no tema de um curta." (VARDA, Agnès. Un minuto para una imagen. In: L'Atalante, jul.-dez 20II, p. 73). 
abandonar nunca o reino do visível. Trata-se apenas de imagens. São objeto - $o$ objeto - da experiência. E de uma experiência conduzida sem ideias de um fim a alcançar, na qual "abre-se um espaço e um tempo para sonhar".

Fotos de animais mortos numa praia, cenas surreais, desenhos infantis, obras primas da pintura, retratos de família - tudo conjugado sobre um mesmo suporte cinematográfico, agenciado numa nova instância do visível, isto é, metaforizado. Não transformado em algo mais interessante ou mais nobre: apenas deslocado.

Se com a fotografia Varda punha em ação o procedimento sob a sua forma mais elementar, com o filme opera o seu desenvolvimento conceptual. Metáfora de uma metáfora, e, contudo, nem um pouco afastada da realidade da ideia, a imagem descobre nas novas proximidades propostas todo o jogo do que é capaz, provocando o nosso olhar, convocando-nos mais uma vez a olhar, "a olhar de novo" - ${ }^{\text {Io }}$ e também a nos questionar sobre o normal e o extraordinário, o real e o imaginário, a verdade e seus simulacros, o humano e sua sombra.

\section{d}

A inexistência de um método para olhar não se deve apenas à multiplicidade de procedimentos que os grandes observadores nos legaram e sempre estão em vias de reinventar. Em certa medida, a própria ideia de um método é um sem-sentido se temos em conta que ver é sempre, também, uma aventura do involuntário. Se, por um lado, somos capazes de realizar uma observação, por outro lado, bem podemos ser tomados por uma visão.

Consideremos o caso mais extraordinário de todos. Em 1979, Werner Herzog começa a ser visitado por uma imagem que o assombra. Nada ao seu alcance pode libertá-lo dela: "Com a fúria enlouquecida de um cão que cravou os dentes na perna de um veado já morto, e puxa do animal caído de tal maneira que o caçador

9 VARDA, Agnès. Une minute pour une image. França, 1982b.

Io "É preciso, por isso, uma espécie de coragem: coragem de olhar, olhar também (...). Não há imagens que, em si, nos deixem mudos, impotentes. Uma imagem da qual não podemos dizer nada é em geral uma imagem à qual não dedicamos o tempo (...) de olhar atentamente." (DIDI-HUBERMAN, Georges. "Inquietar-se diante de cada imagem” (Entrevista realizada por Mathieu Potte- Bonneville \& Pierre Zaoui). In: Vacarme, Paris, $\left.{ }^{\circ} 37,2006\right)$. 
abandona qualquer tentativa de acalmá-lo, se apoderou de mim uma visão: $a$ imagem de um enorme barco a vapor numa montanha".

Herzog acaba de filmar Nosferatu e Woyzeck, filmes aclamados pela crítica, com os quais se consagrou, e seguramente preferiria olhar noutra direção, mas a visão que tomou conta dele o obriga a embarcar numa empresa enlouquecedora. Toda a sua percepção foi alterada. De repente, vê algo que os outros não veem. ${ }^{12}$ Fitzscarrald $o^{13}$ é a história de um aventureiro que sonha construir um teatro no meio da selva, mas isso é apenas uma desculpa, um elaborado MacGuffin, porque Fitzscarraldo é no fundo o recurso excessivo de um cineasta exaltado para dar corpo a essa visão: improvável, surreal, doentia - porém, perfeitamente diferenciada na imaginação de Herzog.

Produtores e assistentes insistirão em ver na visão uma metáfora, quero dizer, uma alegoria, capaz de ser articulada por outras imagens, menos incômodas, menos dispendiosas, menos inconvenientes, mas Herzog defenderá sempre que se trata de uma imagem e não de um símbolo.

Exemplo (5/6/8I):

O que tentavam me dizer? Queriam dissuadir-me de arrastar o barco por cima da montanha, me proteger da minha própria... a palavra loucura apenas foi eludida: não poderia reescrever o roteiro de forma a que Fitzscarraldo não tivesse que arrastar o barco pela montanha? ${ }^{14}$

Exemplo (29/4/198I):

Há um grande problema com Laplace: ele chamou-me à parte e me disse que W. discutia constantemente com ele e que assim não podia seguir trabalhando, que queria ir embora. L. diz que quer aplanar tanto a pendente que só restaria uma inclinação de doze graus, mas isso faria com que parecesse a brecha de um istmo. ${ }^{15}$

${ }^{\text {II } H E R Z O G, ~ W e r n e r . ~ C o n q u i s t a ~ d e ~ l o ~ i n u ́ t i l . ~ B a r c e l o n a: ~ B l a c k i e ~ B o o k s, ~ 20 I 8, ~ p . ~} 5$.

${ }^{\text {I2 }}$ Ibid., p. 293.

${ }^{13}$ O filme se encontra disponível em vários formatos e plataformas. Disponível em: https : //yts.mx/movie/fitzcarraldo-1982.

${ }^{14}$ Op. cit., p. 3 I2.

is Ibid., p. 262. 
Em última instância, se a visão de Herzog, como de resto qualquer imagem incisiva, pode chegar a funcionar como metáfora, o fará - eventualmente - $a$ posteriori, com total indiferença às ilações que possa vir a suscitar (é sempre dessa forma que funcionam as imagens que são objeto de uma experiência estética):

Disse-lhe [a Laplace] que não permitirei isso, porque perderíamos a metáfora central do filme. Metáfora do quê, me perguntou. Disse que isso não sabia, só que era uma grande metáfora. Que quiçá não era senão uma imagem que dormita em todos nós, e que eu sou só aquele que a coloca em contato com um irmão a quem ainda não conheceu. ${ }^{16}$

Metáfora em sentido literal, portanto, que no seu vazio problematiza as fronteiras entre o possível e o impossível, entre o real e o imaginário. Isso significa que a imagem de um barco a vapor numa montanha não é síntese de nada, não é símbolo de coisa nenhuma, mesmo quando aspire a constituir um espaço de encontro para os olhares e peça "consumação, fraternidade". ${ }^{17}$

No fundo, nem o próprio Herzog domina o sentido da sua visão. Ao contrário do capitão holandês do Molly Aida, que diz ter aprendido a diferenciar a realidade das alucinaçôes, Herzog parece dominado por certa exaltação estética, ${ }^{18}$ da qual não parece querer curar-se, vendo na realidade cotidiana apenas uma ilusão detrás da qual se oculta a realidade dos sonhos. ${ }^{19}$

Exemplo (28/5/8I):

K. gritou que eu era um demente, e que aquilo que pretendia fazer era um crime, e eu lhe respondi que se o barco chegava a soltarse ninguém estaria em perigo, que o barco se destruiria num belo

${ }^{16} \mathrm{Id}$.

${ }^{17}$ MERLEAU-PONTY, Maurice. "A linguagem indireta” (1952). In: O homem e a comunicação. A prosa do mundo. Rio de Janeiro, Edições Bloch, 1974, p. 80.

${ }^{18}$ EY, Henri: Tratado de las alucinaciones. Buenos Aires, Polemos, 20ıо, p. пюо.

I9 "Nós não somos capazes de curá-los da ideia de que nossa vida ordinária é só uma ilusão detrás da qual se encontra a realidade dos sonhos.” (HERZOG, Werner. Fitzcarraldo. Peru/Alemanha, 1982, i; 5; 55). 
cataclismo e aí acabaria tudo. Mas esse não era o objetivo do exercício, eu estava aí a serviço de outra visão. ${ }^{20}$

Desta disposição, que para a sua equipe ronda o delírio, ${ }^{21}$ dá mostras o diário que Herzog escreve durante os longos anos da rodagem do filme. Carregado de imagens intensas e insensatas, que interrompem continuamente a narração do difícil processo de produção, as suas páginas revelam o modo em que, como dizia Éluard, "para aquele que vê, o infortúnio desfaz e refaz sem cessar um mundo banal, vulgar, insuportável, impossível”. ${ }^{22}$

Mais profundamente, em virtude dessas imagens, a natureza das coisas reais demonstra não estar longe da natureza das coisas imaginadas, "assim como, graças ao pássaro, a nuvem não está longe do homem”. ${ }^{23}$ Literalidade: as imagens não remetem a um espaço simbólico, mas revelam o modo em que a imaginação sonda e trabalha perfis impensados da realidade.

Em todo o caso, Herzog não se sente dono dessas imagens (pelo contrário). Também não as coloca em jogo com intenção alguma. Digamos, antes, que são simplesmente conjuradas pela sua escrita através do exercício de uma linguagem sem entendimento. ${ }^{24}$ Entre o que compreendemos e o restante (quer o compreendamos, quer não), a sua visão nos convida a adentrar-nos na selva das coisas e dos

${ }^{20}$ HERZOG, Werner. Fitzcarraldo. Peru/Alemanha, 1982, p. 300.

2I "Laplace acha que o terreno é empinado demais, Kinski completamente impossível, ditado pela loucura. Se está convertendo no epicentro do desânimo. Bem visto, é evidente que já ninguém está do meu lado, ninguém, nem um, nem um só. No meio de centenas de extras indígenas, dúzias de trabalhadores florestais, a gente dos barcos, o pessoal da cozinha, a equipe técnica e os atores, a solidão me bateu como um animal gigante e enfurecido. Mas eu vejo algo que os outros não veem.” (HERZOG, Werner. Conquista de lo inútil. Barcelona: Blackie Books, 2018, p. 293) "Hoje foi embora Laplace. Lhe ofereci a mão sem mediar palavra, ele me respondeu com um abraço rápido e forte, em silêncio; nos seus olhos, que olharam-me como se estivesse perdido, notei que me desejava sorte.” (HERZOG, Werner. Conquista de lo inútil. Barcelona, Blackie Books, 2018, p. 301).

${ }^{22}$ ÉLUARD, Paul. Dar a ver. Madri, Árdora Ediciones, 2019, p. Io5. Cf. Também: "Estou a tal ponto habituado a submergir-me no desconhecido que em qualquer outro entorno o modo de existência parece-me exótico e inumano." (Ibid., p. 306). "A minha existência reduziu-se a uma dimensão: um carril e diante dele um barco. Um pouco mais acima, um poste de apoio, ainda não complemente instalado, do qual por assim dizer pendem barco e vida.” (Ibid., p. 308.).

${ }^{23}$ Ibid, p. 126.

${ }^{24}$ BLANCHOT, O livro por vir. São Paulo, Martins Fontes, 2005, p. 301. 
signos ao mesmo tempo em que ele se adentra no labirinto vegetal no qual rodará o seu filme. Tendida como "uma ponte sem pilares sobre um abismo", ${ }^{25}$ assalta a nossa sensibilidade e a nossa imaginação, conduzindo o nosso olhar além da realidade insensível à que parecemos resignados e nos faz penetrar num mundo onde aceitamos o que se nos oferece, sem ideias preconcebidas nem objetivos determinados, deixando que o nosso pensamento vagueie pelas veredas que as suas imagens abrem nesse território sem desbravar. ${ }^{26}$

A conquista do inútil, com toda a sua carga de exploração e sofrimento, coloca em causa os fins da sociedade e a conservação da vida, mas não é apenas um monumento da barbárie, ${ }^{27}$ nem uma metáfora mais do delírio capitalista, porque, opondo-se à razão calculadora, que é própria da vida gregária e afirmando a soberania dos movimentos impulsivos do desejo ${ }^{28}$ interrompe a lógica dos meios

${ }^{25}$ HERZOG, Werner. Conquista de lo inútil. Barcelona, Blackie Books, 2or8, p. 9.

26 "Visão" não quer dizer fantasia. A razão vidente mantém um profundo compromisso com o real. O que se afirma na visão não é algo que não é real - não se trata de um simples devaneio, nem de um erro, nem muito menos uma confusão. O que se afirma na visão é que o real não se esgota nas totalizaçôes estratégicas do sistema da representação - trazendo à luz algo que é negligenciado ou depreciado, omitido ou descartado. A visão não corresponde simplesmente ao real, mas produz ou mobiliza o real, excedendo os limites do possível e do realizável, do verdadeiro e do consensual.

27 "A luta de classes", - escreveu Walter Benjamin -, "que um historiador educado por Marx jamais perde de vista, é uma luta pelas coisas brutas e materiais, sem as quais não existem as refinadas e espirituais. Mas na luta de classes essas coisas espirituais não podem ser representadas como despojos atribuídos ao vencedor. Elas se manifestam nessa luta sob a forma da confiança, da coragem, do humor, da astúcia, da firmeza, e agem de longe, do fundo dos tempos. Elas questionarão sempre cada vitória dos dominadores.” BENJAMIN, Walter. "Teses sobre o conceito de história”. In: Magia e técnica, arte e politica. Ensaios sobre literatura e história da cultura. São Paulo, Brasiliense, 1994, p. 223.

${ }^{28}$ Se damos primazia à literatura, devemos confessar ao mesmo tempo que nos desentendemos do incremento dos recursos da sociedade. Quem quer que dirija a atividade útil - no sentido de um incremento geral das forças - assume interesses opostos aos da literatura. Numa família tradicional, um poeta dilapida o patrimônio e é maldito por isso (BATAILLE, George. La felicidad, el erotismo y la literatura: Ensayos 1944-Ig6I. Buenos Aires: Adriana Hidalgo, 20oI, p. 147) "Acho que nunca assinalaremos o bastante uma primeira incompatibilidade dessa vida sem medida (...), que é o único que conta e é o único sentido de toda a humanidade - em consequência da mesma ação sem medida. (...). Essa incompatibilidade entre a vida sem medida e a ação desmesurada é decisiva para mim” (Ibid., p. 139). 
para os fins, dando tempo para pensar, abrindo espaço para imaginar e para ver o que sempre esteve aí, de outras maneiras. ${ }^{29}$

\section{9}

Existe uma terceira razão pela qual não existe um método para olhar. É que as imagens não se dirigem apenas - nem em primeiro lugar - às nossas faculdades intelectuais, mas ao nosso corpo como um todo. E o corpo, como sabemos, é um meio sujo, não apenas porque conduz processos digestivos e gera dejetos, mas porque comporta uma enorme quantidade de ruído branco.

Ora, sejamos assaltados por uma visão, ou dirijamos o nosso olhar sobre algo, é todo o nosso corpo que entra em jogo, dando lugar a processos complexos, fenômenos sinestésicos e picos de intensidade. Daí que, não apenas as imagens não possam reduzir-se ao domínio do simbólico, mas devam inclusive estender-se do terreno do visível ao mais amplo âmbito do sensível..$^{30}$

Em 1969, em Woodstock, Jimi Hendrix é o último artista que sobe ao cenário. É segunda pela manhã; das quatrocentas mil pessoas que estiveram no festival restam pouco mais de cinquenta mil. Hendrix, que praticamente não dormiu, está acompanhado por um novo grupo de músicos, entre os quais se encontram Billy Cox (baixo) Larry Lee (guitarra), ${ }^{31}$ Mitch Mitchell (bateria), Juma Sultan e Gerardo "Jerry" Velez (percussão). Trata-se de uma experiência - de uma nova experiência. ${ }^{32}$ Os ensaios foram penosos, mas a atuação - de quase duas horas ficará para sempre na memória como uma das melhores do festival.

29 "Vale a pena viver fora, num mundo descodificado e habitado por pessoas cujos costumes foram descodificados?” (Herzog, 2018, p. 166).

${ }^{30}$ Sabemos que não é imprescindível ter olhos para ver. Da mesma forma, não é necessário restringir-se ao visível para dar lugar a uma imagem.

${ }_{31}$ "Foi a única banda de Hendrix que incluiu um segundo guitarrista. Larry Lee apoiava Hendrix numa série de músicas, assumia a guitarra principal em outras, e chegou a cantar numa ou duas." (BRATTIN, Joel. Hendrix and Woodstock: Io Little-Known Facts about the Performance That Defined the '6os. Worcester, 2019. Disponível em: https: //www.wpi.edu/news/ woodstock.)

${ }^{32}$ Hendrix acabara de dissolver The experience. A nova banda Gypsy, Sun and Rainbows, que daria lugar a Band of Gypsys. 
Depois de tocar extensas versões de Message to Love, Hear My Train A Comin', Spanish Castle Magic, Foxy Lady, Jam Back at the House e Izabella, como parte de um longo medley de mais de meia hora, que começa com Voodoo Child e termina com Purple Haze, Hendrix encara solo Star Spangled Banner. ${ }^{33}$ Mesmo não sendo a primeira vez que Hendrix tocava o hino norte-americano, ${ }^{34}$ essa versão seria registada na história como icônica. É curioso que para falar de música se recorra a um adjetivo cuja origem encontra-se na pintura; mas é ainda mais curioso (é sintomático) que, perante as arrepiantes imagens que Hendrix constrói nos intervalos da melodia, se apele ao simbólico para pensá-las.

Em realidade, e muito antes de converter-se no símbolo de uma época, a interpretação de Hendrix contrapõe as imagens da guerra ao mais emblemático dos símbolos pátrios. O tema, composto para ser cantado em uníssono, é interrompido por passagens de improvisação, dando lugar aos uivos da guitarra e o feedback do amplificador, que de forma intensa e imediata, sem elaboração alguma, nos colocam no meio das bombas de napalm e das sirenes das ambulâncias, dos voos rasantes dos avióes e das salvas funerárias.

Ashley Wadleigh lembra que, durante os três minutos e quarenta e três segundos que durou a interpretação de Hendrix, as pessoas agarravam a cabeça, comovidas, atordoadas, contendo a respiração. O hino não estava na lista, confessaria muito mais tarde Billy Cox. Hendrix estava viajando. Nas conferências de imprensa que oferecera a seguir, tentando justificar-se perante os ataques dos quais era vítima, chegaria a dizer que fora uma espécie de flashback.

E era um flashback, certamente, mas não apenas para ele nem apenas da canção que sendo criança era obrigado a cantar na escola. Independentemente das suas intenções, tratando-se ou não de uma forma de protesto, Hendrix dava a ver a todos, através de sons nunca antes escutados numa guitarra, ${ }^{35} \mathrm{em}$ incendiárias

33 Existem numerosas versões disponíveis na internet; disponível em: https://www.youtube.com/watch?v=TKAwPAi4Ni4. Acesso em: 20 nov. 2020.

34 "Há perto de 50 gravaçôes ao vivo de Hendrix tocando o hino, 28 anteriores a Woodstock. A sua extensão vai de um minuto a mais de seis minutos.” (BRATTIN, Joel. Hendrix and Woodstock: Io Little-Known Facts about the Performance That Defined the '6os. Worcester, 2019. Disponível em: https://www.wpi.edu/news/woodstock.)

35 "Ninguém tinha ouvido isso nunca. Pegou a todos de surpresa." (MOORES, Sean. Patriotism or protest? Army vet Jimi Hendrix had the 'most electrifying moment' at Woodstock. 
fulgurações sinestésicas, parte do que acontecia no Vietnã nesse momento. Sem necessidade de palavras, recriava literalmente a paisagem sonora da guerra. ${ }^{36}$ Não havia nada de simbólico nisso. Muito pelo contrário. Distorcendo o simbólico, Hendrix deixava entrever a deflagração do real que tinha lugar sob sua bandeira.

A distorção, no sentido do deslocamento inarmônico - incontrolado e praticamente incontrolável - de uma figura sonora, também é uma forma de abordar a metáfora em sentido literal. O seu objeto (uma nota isolada ou uma passagem complexa) é deslocado (dilacerado) para dar lugar a uma imagem (um conglomerado de perceptos e afetos), nos obrigando a abandonar o plano da representação (dando lugar a um desarranjo dos sentidos e a uma suspensão do sentido).

No lugar do intelecto, o corpo - meio sujo, cheio de ruído branco. No lugar da representação, o mundo - objeto opaco, carregado de estática. ${ }^{37}$ Simples deslocamentos.

Quando voltamos ao registo daquele concerto legendário, resulta comovedor ver o modo em que Hendrix se abandona durante os momentos mais arrebatadores da sua improvisação. Com os olhos fechados, o seu corpo treme freneticamente e relaxa, uma e outra vez, ante os embates das imagens que povoam a sua memória e sobrecarregam a sua sensibilidade. Sem nenhum esforço, atento à estática que

New York, 2019. Disponível em: https://www.stripes.com/news/special-reports/ vietnam-stories/1969/patriotism-or-protest-army-vet-jimi-hendrixhad-the-most-electrifying-moment-at-woodstock-1.594315)

${ }^{36}$ MORELlO, Tom. Tom Morello: This Is My Favorite Jimi Hendrix Song. 2019. (Disponível em: https://www.ultimate-guitar.com/news/general_music_news/ tom_morello_this_is_my_favorite_jimi_hendrix_song.html. Acesso em: 22 out. 2020.) "Em músicas como Machine Gun or Voodoo Child seu instrumento é como uma divining rod dos turbulentos anos sessenta - é possível ouvir os levantamentos nas ruas e as bombas de napalm caindo no seu Star-Spangled Banner. (...) E a música de Hendrix Machine Gun recria a paisagem sonora da guerra do Vietnã através do seu amplificador Marshall duma forma que transmite uma posição política tão claramente como qualquer coisa escrita por Bob Dylan”.

37 "Hendrix foi perseguido para que explicasse as suas motivaçôes. Numa conferência de imprensa algumas semanas depois de Woodstock, Hendrix disse: “Tocamos o hino no clima da América hoje. O ar está ligeiramente estático, né?"” (MOORES, Sean. Patriotism or protest? Army vet Jimi Hendrix had the 'most electrifying moment' at Woodstock. New York, 2019. Disponível em: https://www.stripes.com/news/special-reports/vietnamstories/1969/patriotism-or-protest-army-vet-jimi-hendrix-had-themost-electrifying-moment-at-woodstock-1.594315). 
há no ar, acompanha as modulaçóes do som até o ponto em que tudo ameaça colapsar num uivo ensurdecedor e, sem perder intensidade, o traz de volta ao domínio da música.

Kafka escreveu em sonhos: "Sou o equilibrista que no ar caminha descalço sobre um arame farpado".$^{8}$

\section{g}

Olhar não é nunca um movimento das imagens em direção ao simbólico, mas um processo, sempre imponderável, sempre singular, que vai do mundo ao mundo - através das imagens.

Nessa medida, é sempre, também, um exercício excessivo, no qual nos vemos ultrapassados por tudo aquilo que não tem lugar na ordem da representação. Daí que, quando uma imagem nos alcança com toda a sua carga de realidade, de memória e de utopia, não saibamos, em princípio, o que fazer com ela - como Fouli ao receber de Agnès as pedras e a foto.

Se por costume ou deformação profissional ainda tendemos a ver uma mera metáfora nesse gesto, é apenas porque não terminamos nunca de nos colocar no lugar do espectador que somos: não fora do mundo, mas imersos nele, expostos ao que se dá e aparece, sensíveis e finitos, mas também capazes de fazer pausas, de colocar as coisas no seu lugar e dirigir a vista para aquilo que solicita a nossa atenção - e, quiçá, de articular por metáforas, isto é, de dar a ver, literalmente, através de mil deslocamentos, as imagens capazes de abrir o mundo ao mundo, quero dizer, aos outros e ao tempo, à imaginação e à tarefa da liberdade.

${ }^{38}$ Trata-se de um poema conjetural de Kafka com o qual sonha Marconi em Respiración artificial, a novela de Ricardo Piglia. (PIGLIA, Ricardo. Respiración artificial. Buenos Aires: Pomaire, 1980, p. 147) 


\section{Referências bibliográficas}

BATAILLE, George. La felicidad, el erotismo y la literatura: Ensayos 1944-Ig6I. Buenos Aires: Adriana Hidalgo, $200 \mathrm{.}$

BENJAMIN, Walter. "Teses sobre o conceito de história". In: Magia e técnica, arte e politica. Ensaios sobre literatura e história da cultura. São Paulo: Brasiliense, 1994.

BLANCHOT, Maurice. O livro por vir. São Paulo: Martins Fontes, 2005.

BRATTIN, Joel. Hendrix and Woodstock: Io Little-Known Facts about the Performance That Defined the '6os. Worcester, 2019. Disponível em: https: //www.wpi.edu/news/woodstock. Acesso em: 22 out. 2020.

DIDI-HUBERMAN, Georges. "Inquietar-se diante de cada imagem" (Entrevista realizada por Mathieu Potte- Bonneville \& Pierre Zaoui). In: Vacarme, ${ }^{\circ} 37$, 2006.

ÉLUARD, Paul. Dar a ver. Madri: Árdora Ediciones, 2019.

EY, Henri. Tratado de las alucinaciones. Buenos Aires, 2010.

HERZOG, Werner. Conquista de lo inútil. Barcelona: Blackie Books, 2018.

HERZOG, Werner. Fitzcarraldo. Peru/Alemanha, 1982.

MERLEAU-PONTY, Maurice. "A linguagem indireta" (1952). In: O homem e a comunicação. A prosa do mundo. Rio de Janeiro: Edições Bloch, 1974.

MOORES, Sean. Patriotism or protest? Army vet Jimi Hendrix had the 'most electrifying moment' at Woodstock. New York, 2019. Disponível em: https : // www.stripes.com/news/special-reports/vietnam-stories/1969/ patriotism-or-protest-army-vet-jimi-hendrix-had-the-mostelectrifying-moment-at-woodstock-1.594315. Acesso em: 22 out. 2020

MORELLO, Tom. Tom Morello: This Is My Favorite Jimi Hendrix Song. 2019. Disponível em: https:// www.ultimate-guitar.com/news/general_music_news/ tom_morello_this_is_my_favorite_jimi_hendrix_song.html.

Acesso em: 22 out. 2020.

PIGLIA, Ricardo. Respiración artificial. Buenos Aires: Pomaire, 1980. VARDA, Agnès. "Un minuto para una imagen”. In: L'Atalante, jul.-dez. 2oIr. VARDA, Agnès. Ulysse. França, 1982. 
VARDA, Agnès. Une minute pour une image. França, 1982b.

\section{g}

Resumo: Colocar fora de lugar aquilo que de ordinário damos por assente, instalar o extraordinário no âmbito do familiar, dar corpo a imagens desfazem e refazem sem cessar um mundo banal, ou distorcer os símbolos sob os quais tende a ocultar-se a doação e a exigência do real, são procedimentos estéticos que devolvem o seu sentido literal à metáfora e, como tais, restituem uma potência própria da arte que passa despercebida quando pensada sob o horizonte do sistema da representação. Procurando ser fiel às experiências de Varda, Herzog e Hendrix, o presente ensaio procura articular elementos para repensar esse conceito chave da estética, ao mesmo tempo em que visa situar o labor artístico nesse cruzamento do dado e do imaginário, do involuntário e do voluntário, da realidade e do desejo.

Palavras-Chave: metáfora; literalidade; Agnès Varda; Werner Herzog; Jimi Hendrix.
Abstract: Staging out of the ordinary what we take for granted, installing the extraordinary within the familiar, giving body to images that undo and remake a banal world, or distorting the symbols under which the donation of the real tends to be hidden, are aesthetic procedures that restores its literal meaning to metaphor and, by that, the power art (power that goes unnoticed when thought in the context of the system of representation). Trying to be faithful to the experiences of Varda, Herzog and Hendrix, this essay seeks to articulate elements to rethink this key concept of aesthetics, at the same time that it aims to situate artistic work in this intersection of what is given and the imaginary, the involuntary and the voluntary, reality and desire.

KeYwords: metaphor; literality; Agnès Varda; Werner Herzog; Jimi Hendrix. 